\title{
Fatty acid composition of lipids in pot marigold (Calendula officinalis L.) seed genotypes
}

\author{
Francisc V Dulf, Doru Pamfil, Adriana D Baciu* and Adela Pintea
}

\begin{abstract}
Background: Calendula officinalis L. (pot marigold) is an annual aromatic herb with yellow or golden-orange flowers, native to the Mediterranean climate areas. Their seeds contain significant amounts of oil (around 20\%), of which about $60 \%$ is calendic acid. For these reasons, in Europe concentrated research efforts have been directed towards the development of pot marigold as an oilseed crop for industrial purposes.

Results: The oil content and fatty acid composition of major lipid fractions in seeds from eleven genotypes of pot marigold (Calendula officinalis L.) were determined. The lipid content of seeds varied between 13.6 and $21.7 \mathrm{~g}$ oil/100 g seeds. The calendic and linoleic acids were the two dominant fatty acids in total lipid (51.4 to $57.6 \%$ and 28.5 to 31.9\%) and triacylglycerol (45.7 to $54.7 \%$ and 22.6 to $29.2 \%$ ) fractions. Polar lipids were also characterised by higher unsaturation ratios (with the PUFAs content between 60.4 and 66.4\%), while saturates (consisted mainly of palmitic and very long-chain saturated fatty acids) were found in higher amounts in sterol esters (ranging between 49.3 and $55.7 \%$ of total fatty acids).

Conclusions: All the pot marigold seed oils investigated contain high levels of calendic acid (more than 50\% of total fatty acids), making them favorable for industrial use. The compositional differences between the genotypes should be considered when breeding and exploiting the pot marigold seeds for nutraceutical and pharmacological purposes.
\end{abstract}

Keywords: Calendula officinalis L., Conjugated linolenic acids, Pot marigold, Seed oils, Fatty acids, Polar lipids, Triacylglycerols, Sterol esters, GC-MS

\section{Background}

Calendula officinalis L. (pot marigold), a member of the Asteraceae family, is an annual aromatic herb with yellow or golden-orange flowers, native to the Mediterranean climate areas, being also successfully cultivated in temperate regions of the Earth for ornamental and medicinal purposes [1]. The species have been reported to contain a variety of phytochemicals, including carbohydrates, lipids, phenolic compounds, steroids, terpenoids, tocopherols, carotenoids and quinones [2-5] with potential health benefits [1,6-10].

Besides the usual fatty acids, a few plants are capable to biosynthesize some unusual fatty acids, with special chemical structure. Usually these fatty acids accumulate in storage tissues, while in green organs they are absent or present in very small amounts. The presence of unusual fatty acids is genetically determined and they are

\footnotetext{
* Correspondence: adriana11_baciu@yahoo.com

University of Agricultural Sciences and Veterinary Medicine, Manastur 3-5, Cluj-Napoca 400372, Romania
}

highly significant indicators of phylogenetic relationships $[11,12]$. The seeds of pot marigold have a significant oil content (around 20\%), of which about $60 \%$ is the unusual calendic acid $(8 t, 10 \mathrm{t}, 12 \mathrm{c}-18: 3)$ [13-16]. Several studies demonstrated that calendic acid is synthesized in Calendula seeds via desaturation of linoleic acid [17-21]. Due to its special structure - with three conjugated double bonds - calendic acid and Calendula seeds oil exhibit interesting chemical and physiological properties.

The seed oils such of Calendula officinalis L., Momordica charantia L. or Aleurites fordii Hemsl., rich in conjugated linolenic acids (CLNAs) have a high rate of oxidation and are used as raw materials in paints and coatings industry, and have applications in the manufacture of cosmetics and some industrial polymers [19,22-24]. For these reasons, in the last few years, a concentrated research effort in Europe has been directed towards the development of Calendula officinalis L. as an oilseed crop for industrial purposes [25] and for the engineering of 
transgenic plants containing the metabolic route for the conjugated fatty acids biosynthesis [26,27].

The increasing interest for plants producing conjugated fatty acids is also motivated by the recent findings related to their biological effects. It has been shown that CLNAs have an important body fatlowering effect [28] and possess anti-carcinogenic properties, exhibiting apoptotic activity against a wide variety of tumor cells, such as the U-937 human leukemic cancer cell line and the colon cancer cells (Caco-2) [24,29,30]. Bhaskar et al. [31] observed that the trans CLNAs exhibited stronger growth inhibition and more DNA fragmentation in human colon cancer cells than corresponding cis CLNA isomers.

To our knowledge, all the studies, excepting two short reports of Ul'chenko et al. [32] and Pintea et al. [33], respectively, conducted on marigold seed oils determined the fatty acid contents by analyzing only the total lipid matrix.

Therefore, the aim of the present investigation was to compare the oil content and fatty acid compositions of total lipids (TLs), triacylglycerols (TAGs), polar lipids (PLs) and sterol esters (SEs) in seeds of eleven pot marigold genotypes from six different locations in Europe, grown in the Transylvanian region (Romania). The information obtained is helpful to identify suitable genotypes for use in breeding programs of Calendula officinalis.

\section{Results and discussion}

\section{Oil contents}

The oil (total lipids) contents in eleven genotypes of pot marigold (Calendula officinalis L.) (CO) seeds are presented in Figure 1.The values were found to vary between 13.6- 21.7 (g oil/100 g seeds). There were no significant

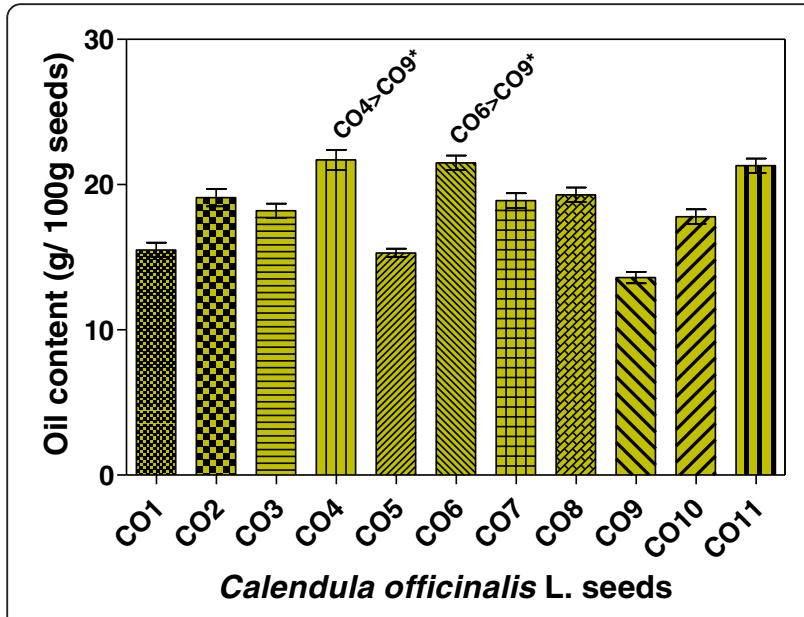

Figure 1 The oil content of Pot marigold (Calendula officinalis L.) seeds. CO1- CO11, pot marigold (Calendula officinalis L.) genotypes. Results are given as mean $\pm \mathrm{SD}(\mathrm{n}=3)$; * - significant difference, $p<0.05$ (using "Kruskal-Wallis non-parametric test" followed by "Dunn's Multiple Comparison Test"). differences $(p<0.05)$ among genotypes, except for oil contents of samples $\mathrm{CO} 4$ and $\mathrm{CO} 6$ versus $\mathrm{CO}$. The highest amounts of oils were found in the $\mathrm{CO} 4(21.7 \mathrm{~g} / 100 \mathrm{~g})$, CO6 (21.5 g/100 g) and CO11 (21.3 g/100 g), whereas the genotypes CO1 (15.5 g/100 g), CO5 (15.3 g/100 g) and CO9 $(13.6 \mathrm{~g} / 100 \mathrm{~g})$, exhibited the lowest contents of the TLs. These values were similar to those reported by Cromack and Smith [25] but much higher than those observed by Ozgul- Yucel (5.9\% oil in Turkish Calendula seeds) [34] and Angelini et al. (5.4\% oil in Italian CO seed crops from 1994) [35]. The TLs content of the analyzed $\mathrm{CO}$ seeds in this study were also comparable with those of some non-conventional vegetable oil sources with unique phytochemical compositions, such as bitter gourd (21\%), cherry laurel (18.3\%), pomegranate (18.1\%), blackthorn (16.5\%), linseed dodder (15.5-20.7\%), and coriander $(12.7-18 \%)$ seeds $[34,35]$.

\section{Fatty acid composition}

The total lipid fatty acid composition as well as the fatty acid composition of TAGs, PLs and SEs of the analyzed pot marigold seed oils is presented in Tables 1 and 2 .

\section{TL fatty acids}

Nineteen fatty acids were identified in the studied pot marigold seed oils (Figure 2), including very low amounts of a hydroxy fatty acid, namely 9- hydroxy- trans-10, cis-12 octadecadienic-acid (9-HODE).

As expected, calendic acid [18:3 $(8 t, 10 t, 12 c)(\mathrm{n}-6)]$ was the predominant polyunsaturated fatty acid (PUFA) in all TL extracts, and its composition varied between $51.47 \%$ (in CO8) and $57.63 \%$ of total fatty acids (in $\mathrm{CO} 4)$. The next most abundant fatty acid was linoleic acid [18:2 (n-6)] (28.50 to $31.86 \%)$, followed by oleic [18:1 (n-9)] (4.44 to 6.25\%) and palmitic acids (16:0) (3.86 to $4.55 \%$ ). Small and very small (or trace) amounts $(<2 \%)$ of stearic (18:0), $\beta$ - calendic [18:3 $(8 t, 10 t, 12 t)$ $(\mathrm{n}-6)]$, elaidic [18:1 (9t) (n-9)], arachidic (20:0), behenic (22:0), gondoic [20:1 (n-9)], $\alpha$ - linolenic [18:3 (n-3)], linoelaidicic [18:2 $(9 t, 12 t)(\mathrm{n}-6)]$, cis-7 hexadecenoic [16:1 (n-9)], palmitoleic [16:1 (n-7)], lauric (12:0), myristic (14:0), pentadecanoic (15:0), and margaric (17:0) acids were also determined. Similar results for the calendic acid content (over 50\%) were reported by Cromack and Smith [25] for two of nine hybrids of pot marigold seeds grown in England, as well as by Cahoon et al. [26]. Ozgul- Yucel concluded that Turkish calendula seed oil is characterized by high concentration of linoleic acid (43.5\%) and low content of CLNAs (calendic acid $(18.3 \%)+\beta$ - calendic (11.2\%)) [34]. Moreover, the calendic acid levels reported here are considerably higher than those reported previously by Suzuki et al. [29] (33.4\%) and Angelini et al. [35] (16-46\%- in the Italian pot marigold seed oils, crops from 1993). 
Table 1 Fatty acid composition (\%) in total lipids and individual lipid classes of different genotypes of pot marigold seed oils

\begin{tabular}{|c|c|c|c|c|c|c|c|c|c|c|c|c|c|c|c|c|c|c|c|}
\hline \multirow[t]{2}{*}{ Species } & \multicolumn{19}{|c|}{ Fatty acids (\%w/w of total fatty acids) } \\
\hline & $12: 0$ & 14:0 & 15:0 & $\begin{array}{l}16: 1 \\
(n-9)\end{array}$ & $\begin{array}{l}16: 1 \\
(n-7)\end{array}$ & $16: 0$ & $17: 0$ & $\begin{array}{l}18: 2 \\
(n-6)\end{array}$ & $\begin{array}{l}18: 1 \\
(n-9)\end{array}$ & $\begin{array}{l}18: 1 \\
(9 t) \\
(n-9)\end{array}$ & $\begin{array}{c}18: 2 \\
(9 t, 12 t) \\
(n-6)\end{array}$ & 18:0 & $\begin{array}{l}18: 3 \\
(n-3)\end{array}$ & $\begin{array}{c}18: 3 \\
(8 t, 10 t \\
12 c) \\
(n-6)\end{array}$ & $\begin{array}{l}20: 1 \\
(n-9)\end{array}$ & $\begin{array}{c}18: 3 \\
(8 t, 10 t \\
12 t) \\
(n-6)\end{array}$ & $20: 0$ & 9-HODE & $22: 0$ \\
\hline \multicolumn{20}{|l|}{$\mathrm{CO1}$} \\
\hline $\mathrm{TL}$ & 0.02 & 0.18 & 0.01 & 0.03 & 0.08 & 4.05 & 0.03 & 30.05 & 4.99 & 0.51 & $\operatorname{tr}$ & 1.87 & 0.09 & 55.93 & 0.14 & 0.85 & 0.36 & 0.63 & 0.18 \\
\hline TAG & nd & 0.15 & 0.08 & 0.03 & 0.08 & 5.62 & $\operatorname{tr}$ & 29.18 & 5.76 & 0.50 & nd & 2.62 & 0.15 & 54.67 & 0.10 & 0.60 & 0.46 & nd & nd \\
\hline$P L$ & 0.64 & 3.88 & 0.27 & 0.31 & 0.15 & 17.08 & nd & 60.78 & 6.49 & 0.70 & tr & 3.72 & nd & 4.29 & tr & 0.43 & 0.59 & tr & 0.67 \\
\hline SE & 0.62 & 2.86 & nd & tr & nd & 20.02 & nd & 34.91 & 11.02 & 0.12 & nd & 2.53 & nd & 4.64 & nd & nd & 2.45 & nd & 20.83 \\
\hline \multicolumn{20}{|l|}{$\mathrm{CO} 2$} \\
\hline $\mathrm{TL}$ & 0.03 & 0.30 & 0.01 & 0.03 & 0.07 & 4.33 & 0.04 & 28.50 & 4.49 & 0.53 & 0.02 & 1.84 & 0.10 & 57.22 & 0.16 & 0.77 & 0.42 & 0.89 & 0.25 \\
\hline TAG & nd & 0.13 & 0.02 & 0.04 & 0.18 & 7.98 & 0.04 & 25.10 & 9.10 & 1.10 & nd & 3.95 & 0.09 & 50.03 & 0.47 & 0.70 & 1.07 & nd & nd \\
\hline$P L$ & 0.41 & 4.44 & 0.15 & 0.16 & 0.08 & 20.61 & 0.17 & 55.02 & 7.04 & 1.01 & 1.06 & 3.94 & nd & 3.98 & 0.07 & 0.40 & 0.61 & 0.17 & 0.68 \\
\hline SE & 0.91 & 3.05 & nd & 0.39 & nd & 20.23 & nd & 33.75 & 10.32 & 0.14 & nd & 2.97 & nd & 4.94 & nd & nd & 2.53 & nd & 20.77 \\
\hline \multicolumn{20}{|l|}{$\mathrm{CO} 3$} \\
\hline $\mathrm{TL}$ & 0.01 & 0.15 & 0.01 & 0.03 & 0.07 & 3.93 & 0.02 & 31.79 & 5.06 & 0.54 & 0.06 & 1.73 & 0.10 & 54.07 & 0.15 & 0.79 & 0.38 & 0.95 & 0.17 \\
\hline TAG & nd & 0.14 & 0.02 & 0.04 & 0.18 & 10.21 & 0.07 & 24.30 & 10.02 & 0.73 & nd & 4.08 & 0.10 & 48.53 & 0.45 & 0.53 & 0.60 & nd & nd \\
\hline$P L$ & 0.17 & 2.45 & 0.12 & 0.13 & 0.12 & 17.66 & 0.15 & 61.33 & 6.88 & 1.13 & 0.76 & 3.43 & nd & 3.86 & tr & 0.46 & 0.50 & 0.13 & 0.72 \\
\hline SE & 0.72 & 2.53 & nd & 0.33 & nd & 22.77 & nd & 32.34 & 12.00 & 0.20 & nd & 2.93 & nd & 2.69 & nd & nd & 2.49 & nd & 21.00 \\
\hline \multicolumn{20}{|l|}{$\mathrm{CO} 4$} \\
\hline $\mathrm{TL}$ & 0.02 & 0.19 & 0.01 & 0.04 & 0.06 & 4.55 & 0.02 & 28.52 & 4.44 & 0.41 & 0.01 & 1.77 & 0.13 & 57.63 & 0.14 & 0.91 & 0.35 & 0.66 & 0.12 \\
\hline TAG & nd & 0.15 & 0.03 & 0.08 & 0.18 & 8.59 & 0.04 & 23.32 & 10.79 & 1.20 & nd & 4.20 & 0.08 & 49.02 & 0.53 & 0.51 & 1.28 & nd & nd \\
\hline$P L$ & 0.22 & 2.29 & 0.12 & 0.26 & 0.12 & 16.55 & 0.16 & 61.15 & 8.13 & 1.30 & 0.74 & 3.18 & nd & 4.19 & 0.10 & 0.34 & 0.46 & 0.16 & 0.53 \\
\hline SE & 1.24 & 2.05 & 0.38 & 0.78 & nd & 21.78 & nd & 32.41 & 11.80 & 1.53 & nd & 3.51 & nd & 3.93 & nd & nd & 2.68 & nd & 17.91 \\
\hline \multicolumn{20}{|l|}{$\mathrm{CO}$} \\
\hline $\mathrm{TL}$ & 0.02 & 0.22 & 0.01 & 0.03 & 0.07 & 4.22 & 0.03 & 31.47 & 6.19 & 0.55 & 0.07 & 1.88 & 0.11 & 52.52 & 0.15 & 0.83 & 0.40 & 0.98 & 0.25 \\
\hline TAG & nd & 0.15 & 0.02 & 0.05 & 0.25 & 8.15 & 0.04 & 24.75 & 13.27 & 1.15 & nd & 4.24 & 0.07 & 46.00 & 0.58 & 0.38 & 0.90 & nd & nd \\
\hline$P L$ & 0.26 & 3.23 & 0.16 & 0.17 & 0.12 & 20.31 & 0.19 & 57.96 & 7.69 & 1.20 & 0.77 & 3.68 & nd & 2.66 & 0.04 & 0.16 & 0.59 & 0.11 & 0.70 \\
\hline SE & 1.01 & 2.11 & nd & tr & nd & 19.70 & nd & 33.52 & 10.31 & 0.37 & nd & 4.65 & nd & 4.60 & nd & nd & 2.80 & nd & 20.93 \\
\hline \multicolumn{20}{|l|}{$\mathrm{CO} 6$} \\
\hline $\mathrm{TL}$ & 0.02 & 0.21 & 0.02 & 0.04 & 0.06 & 4.48 & 0.04 & 29.49 & 5.26 & 0.55 & 0.02 & 1.83 & 0.09 & 55.80 & 0.13 & 0.66 & 0.34 & 0.89 & 0.07 \\
\hline TAG & nd & 0.16 & 0.02 & 0.07 & 0.22 & 9.55 & 0.06 & 22.60 & 12.01 & 1.34 & nd & 4.42 & 0.06 & 47.85 & 0.48 & 0.33 & 0.83 & nd & nd \\
\hline$P L$ & 0.35 & 2.83 & 0.21 & 0.18 & 0.10 & 20.14 & 0.21 & 59.04 & 7.51 & 1.24 & 0.61 & 3.72 & nd & 2.61 & tr & 0.13 & 0.59 & 0.06 & 0.47 \\
\hline SE & 1.59 & 2.90 & nd & tr & nd & 20.37 & nd & 32.33 & 12.29 & 0.17 & nd & 3.97 & nd & 3.75 & nd & nd & 2.85 & nd & 19.78 \\
\hline \multicolumn{20}{|l|}{$\mathrm{CO} 7$} \\
\hline $\mathrm{TL}$ & 0.02 & 0.33 & 0.02 & 0.03 & 0.08 & 4.54 & 0.04 & 30.26 & 6.04 & 0.57 & 1.66 & 1.84 & 0.08 & 53.17 & ir & 0.46 & 0.38 & 0.38 & 0.11 \\
\hline TAG & nd & 0.16 & 0.02 & 0.10 & 0.22 & 8.62 & 0.08 & 24.62 & 12.65 & 1.13 & nd & 4.03 & 0.08 & 46.46 & 0.57 & 0.44 & 0.82 & nd & nd \\
\hline$P L$ & 0.29 & 2.74 & 0.13 & 0.16 & 0.14 & 19.90 & 0.22 & 60.46 & 7.20 & 1.13 & tr & 3.33 & nd & 2.77 & 0.11 & 0.13 & 0.53 & 0.11 & 0.65 \\
\hline SE & 2.19 & 2.80 & nd & 0.71 & nd & 18.31 & nd & 33.89 & 10.83 & 0.22 & nd & 3.30 & nd & 3.77 & nd & nd & 3.32 & nd & 20.66 \\
\hline \multicolumn{20}{|l|}{$\mathrm{CO}$} \\
\hline $\mathrm{TL}$ & 0.05 & 0.39 & 0.01 & 0.02 & 0.11 & 4.11 & 0.03 & 31.86 & 6.25 & 0.49 & 1.80 & 1.99 & 0.11 & 51.47 & 0.02 & 0.48 & 0.41 & 0.24 & 0.17 \\
\hline TAG & nd & 0.16 & 0.02 & 0.05 & 0.29 & 8.26 & 0.05 & 23.37 & 14.32 & 1.11 & nd & 4.77 & 0.06 & 45.73 & 0.53 & 0.43 & 0.85 & nd & nd \\
\hline PL & 0.28 & 2.34 & 0.16 & 0.25 & 0.14 & 19.37 & 0.22 & 58.97 & 8.82 & 1.22 & 0.24 & 3.63 & nd & 2.91 & tr & 0.19 & 0.54 & 0.13 & 0.59 \\
\hline SE & 1.75 & 3.14 & nd & 1.51 & nd & 23.77 & nd & 27.46 & 10.07 & 0.48 & nd & 3.03 & nd & 4.74 & nd & nd & 3.76 & nd & 20.29 \\
\hline
\end{tabular}




\begin{tabular}{|c|c|c|c|c|c|c|c|c|c|c|c|c|c|c|c|c|c|c|c|}
\hline \multicolumn{20}{|l|}{$\mathrm{CO9}$} \\
\hline $\mathrm{TL}$ & 0.03 & 0.19 & 0.02 & 0.02 & 0.10 & 3.98 & 0.05 & 30.81 & 4.98 & 0.53 & 1.34 & 1.87 & 0.12 & 54.21 & tr & 0.58 & 0.39 & 0.27 & 0.51 \\
\hline TAG & nd & 0.11 & 0.03 & 0.04 & 0.25 & 6.49 & 0.07 & 27.68 & 8.94 & 1.01 & nd & 3.59 & 0.10 & 50.06 & 0.47 & 0.53 & 0.63 & nd & nd \\
\hline$P L$ & 0.19 & 1.14 & 0.16 & 0.26 & 0.23 & 20.82 & 0.24 & 59.34 & 7.28 & 1.22 & 0.88 & 3.58 & nd & 2.95 & 0.05 & 0.17 & 0.62 & 0.10 & 0.77 \\
\hline SE & 1.50 & 3.58 & nd & 1.05 & nd & 20.42 & nd & 32.38 & 9.68 & 0.24 & nd & 2.88 & nd & 3.69 & nd & nd & 3.37 & nd & 21.21 \\
\hline \multicolumn{20}{|c|}{$\mathrm{CO} 10$} \\
\hline $\mathrm{TL}$ & 0.02 & 0.16 & 0.02 & 0.02 & 0.12 & 3.86 & 0.03 & 30.99 & 4.97 & 0.53 & 1.71 & 1.87 & 0.11 & 53.88 & tr & 0.65 & 0.36 & 0.29 & 0.41 \\
\hline TAG & nd & 0.08 & 0.01 & 0.05 & 0.31 & 6.99 & 0.05 & 27.93 & 9.09 & 1.06 & nd & 3.76 & 0.07 & 49.18 & 0.43 & 0.41 & 0.58 & nd & nd \\
\hline$P L$ & 0.12 & 0.95 & 0.15 & 0.25 & 0.25 & 20.28 & 0.27 & 61.51 & 6.98 & 1.16 & 0.35 & 3.51 & nd & 2.84 & 0.05 & 0.20 & 0.55 & 0.09 & 0.49 \\
\hline SE & 1.86 & 3.31 & nd & $\mathrm{tr}$ & nd & 20.83 & nd & 32.16 & 10.11 & 0.23 & nd & 3.47 & nd & 3.43 & tr & nd & 3.62 & nd & 20.98 \\
\hline \multicolumn{20}{|c|}{ CO11 } \\
\hline $\mathrm{TL}$ & 0.03 & 0.38 & 0.02 & 0.04 & 0.05 & 4.43 & 0.04 & 30.32 & 4.78 & 0.56 & 0.62 & 1.75 & 0.11 & 55.32 & 0.05 & 0.61 & 0.39 & 0.21 & 0.31 \\
\hline TAG & nd & 0.13 & 0.02 & 0.07 & 0.21 & 7.79 & 0.04 & 27.44 & 8.36 & 1.15 & nd & 3.43 & 0.09 & 49.85 & 0.39 & 0.48 & 0.55 & nd & nd \\
\hline$P L$ & 0.33 & 2.36 & 0.15 & 0.45 & 0.09 & 20.98 & 0.25 & 59.55 & 7.71 & 1.24 & tr & 3.31 & nd & 2.34 & tr & 0.13 & 0.51 & 0.04 & 0.56 \\
\hline SE & 1.57 & 3.36 & nd & tr & nd & 20.93 & nd & 31.84 & 10.88 & 0.19 & nd & 3.26 & nd & 3.19 & nd & nd & 3.61 & nd & 21.17 \\
\hline
\end{tabular}

The values represent the means of three samples, analyzed individually in triplicate $(n=3 \times 3)$. CO1- CO11, pot marigold (Calendula officinalis L.) genotypes.

TL- total lipids, TAG- triacylglycerols, PL- polar lipids, SE- sterol esters, nd- not detected, tr- trace.

The available literature shows that the fatty acid composition of oil seeds varies strongly according to their origin/genotype, and geographical/climatic conditions of the growth areas $[25,36]$. It was also found that the maturity stage of the seeds is an important factor that influences the accumulation of calendic acid in calendula seeds oil. Pintea et al. [33] showed that during the maturation period of the pot marigold seeds $(0-2$ weeks after flower drops) the concentration of calendic acid increased sharply and steadily (from $8.62 \%$ to $53 \%$ ), accompanied by a decrease in the amounts of linoleic and oleic acids. These observations are in agreement with the presence of the specific conjugase which is able to convert linoleic acid into calendic acid in Calendula seeds $[18,26]$. The stereospecific analysis of TAG proved that calendic acid preferentially esterifies the $s n-2$ position of TAG [26,37].

The analysis of fatty acids classes showed statistically significant differences $(p<0.05)$ with the exception of PUFAs (Figure 3). The highest value of saturated fatty acid (SFAs) $(p<0.05)$ was registered in the TLs of Czech genotypes (CO11) (7.34\%), whereas $\mathrm{CO} 5, \mathrm{CO} 7$ and $\mathrm{CO} 8$ were the richest sources of monounsaturated fatty acids (MUFAs) (Figure 3A). On the other hand, small variations $(p<0.05)$ were found in CLNAs contents (Figure 3B), with the highest proportions in $\mathrm{CO} 4$ (58.54\%) and the lowest in CO8 (51.95\%), respectively. As shown in Table 2, the levels of the PUFAs/SFAs (saturated fatty acids) ratios were significantly higher $(p<0.05)$ in TLs (due to the high values of $18: 3$ and 18:2 fatty acids) than in the lipid fractions (TAGs, PLs and SEs) of each pot marigold genotypes.

\section{TAG fatty acids}

The fatty acid profiles of the TAGs were similar to that of the profiles of the TL fractions, due to the dominance of the PUFAs (18:3 and 18:2 (n-6) fatty acids) in their compositions (see Tables 1 and 2) and due to the fact that TAG are major components of the seeds oil.

\section{PL and SE fatty acids}

The fatty acid composition of the PLs and SEs was different from that of the TL and TAG fractions in all the pot marigold genotypes analyzed (Tables 1 and 2).

The PL fractions were highly unsaturated, with the linoleic acid content ranging from 55.02\% (CO2) to 61.51\% (CO10) of total fatty acids. Ul'chenko et al. [32] studied the fatty acid compositions of the lipids from seeds, leaves and flowers of Calendula officinalis L. and reported lower value of linoleic acid (24.5\%) in the phospholipids of seeds, than those determined in the present work.

With four exceptions (samples CO1-4), the calendic acid content in the PL fractions was lower than 3\% (Table 1). This conjugated fatty acid was found to be below 1\% in the phosphatidylcholine (PC) of Calendula officinalis seeds oil [26] or was not detected [32]. The differences between the reported data and our data can be explained by the fact that we have investigated the total polar lipids fraction which includes phospholipids 
Table 2 The composition (\%) of fatty acid classes in total lipids and major lipid fractions from different genotypes of pot marigold seed oils

\begin{tabular}{|c|c|c|c|c|c|c|c|c|c|c|c|}
\hline \multirow[t]{3}{*}{ Species } & \multicolumn{11}{|c|}{ Fatty acids (\%w/w of total fatty acids) } \\
\hline & \multicolumn{2}{|c|}{$\sum$ SFAs } & \multicolumn{2}{|c|}{$\sum$ MUFAs } & \multicolumn{2}{|c|}{$\sum$ PUFAs } & \multicolumn{2}{|c|}{$\sum$ VLCSFAs $(\geq 20 C)$} & \multicolumn{2}{|c|}{$\sum$ CLNAs } & \multirow{2}{*}{$\begin{array}{l}\text { PUFAs } \\
\text { SFAs }\end{array}$} \\
\hline & Mean & SD & Mean & SD & Mean & SD & Mean & SD & Mean & SD & \\
\hline \multicolumn{12}{|l|}{$\mathrm{CO} 1$} \\
\hline $\mathrm{TL}$ & $6.70_{d}$ & 0.25 & $5.75_{d}$ & 0.18 & $86.83 a$ & 2.25 & $0.54_{b}$ & 0.02 & $56.78_{a}$ & 1.76 & $12.96_{a}$ \\
\hline TAG & $8.93_{c}$ & 0.35 & $6.47_{c}$ & 0.20 & $84.45 a$ & 2.30 & $0.46_{b}$ & 0.03 & $55.27 a$ & 1.55 & $9.46_{b}$ \\
\hline$P L$ & $26.85_{b}$ & 1.11 & $7.65_{b}$ & 0.22 & $65.50_{b}$ & 1.85 & $1.26_{b}$ & 0.04 & $4.72_{b}$ & 0.15 & $2.44_{c}$ \\
\hline SE & $49.31_{a}$ & 1.68 & $11.14_{a}$ & 0.32 & $39.55_{c}$ & 1.68 & $23.28 a$ & 1.05 & $4.64 b$ & 0.12 & $0.80_{d}$ \\
\hline \multicolumn{12}{|l|}{$\mathrm{CO} 2$} \\
\hline $\mathrm{TL}$ & $7.23_{d}$ & 0.22 & $5.27_{c}$ & 0.15 & $86.52_{a}$ & 2.30 & $0.67_{b}$ & 0.03 & $57.99 a$ & 1.65 & $11.97 a$ \\
\hline TAG & $13.19_{c}$ & 0.30 & $10.89 a$ & 0.22 & $75.83_{b}$ & 2.27 & $1.07_{b}$ & 0.03 & $50.73_{b}$ & 1.38 & $5.75_{b}$ \\
\hline$P L$ & $31.01_{b}$ & 1.10 & $8.36_{b}$ & 0.18 & $60.46_{c}$ & 2.10 & $1.29 \mathrm{~b}$ & 0.05 & $4.38_{c}$ & 0.12 & $1.95_{c}$ \\
\hline SE & $50.46_{a}$ & 1.80 & $10.85_{a}$ & 0.20 & $38.69_{d}$ & 1.50 & $23.30_{a}$ & 0.70 & $4.94_{c}$ & 0.15 & $0.77_{d}$ \\
\hline \multicolumn{12}{|l|}{$\mathrm{CO} 3$} \\
\hline $\mathrm{TL}$ & $6.39_{d}$ & 0.19 & $5.85_{d}$ & 0.16 & $86.70_{a}$ & 2.38 & $0.54_{b}$ & 0.03 & $54.85 a$ & 1.32 & $13.56_{a}$ \\
\hline TAG & $15.12_{c}$ & 0.35 & $11.42_{b}$ & 0.25 & $73.36_{b}$ & 1.95 & $0.60_{b}$ & 0.03 & $49.06_{b}$ & 1.75 & $4.85 b$ \\
\hline$P L$ & $25.20_{b}$ & 0.80 & $8.26_{c}$ & 0.18 & $66.41_{c}$ & 1.55 & $1.22_{b}$ & 0.04 & $4.32_{c}$ & 0.11 & $2.64_{c}$ \\
\hline SE & $52.44_{a}$ & 1.60 & $12.53_{a}$ & 0.30 & $35.03_{d}$ & 1.15 & $23.49 a$ & 0.56 & $2.69_{c}$ & 0.10 & $0.67 d$ \\
\hline \multicolumn{12}{|l|}{$\mathrm{CO} 4$} \\
\hline $\mathrm{TL}$ & $7.04_{d}$ & 0.16 & $5.09_{d}$ & 0.15 & $87.08_{a}$ & 2.42 & $0.47_{b}$ & 0.02 & $58.54 a$ & 1.58 & $12.37 \mathrm{a}$ \\
\hline TAG & $14.29_{c}$ & 0.31 & $12.78_{b}$ & 0.23 & $72.85 b$ & 2.10 & $1.28_{b}$ & 0.03 & $49.53_{b}$ & 1.65 & $5.10_{b}$ \\
\hline$P L$ & $23.51_{b}$ & 0.62 & $9.91_{c}$ & 0.22 & $66.42_{c}$ & 1.60 & $0.99_{b}$ & 0.03 & $4.53_{c}$ & 0.14 & $2.83_{c}$ \\
\hline SE & $49.55_{a}$ & 1.55 & $14.11_{\mathrm{a}}$ & 0.35 & $36.34_{d}$ & 1.11 & $20.59 a$ & 0.50 & $3.93_{c}$ & 0.11 & $0.73_{d}$ \\
\hline \multicolumn{12}{|l|}{$\mathrm{CO}$} \\
\hline $\mathrm{TL}$ & $7.03_{d}$ & 0.17 & $6.99_{d}$ & 0.15 & $84.89 a$ & 2.30 & $0.66_{b}$ & 0.04 & $53.35 a$ & 1.25 & $12.08_{a}$ \\
\hline TAG & $13.50_{c}$ & 0.28 & $15.30_{a}$ & 0.32 & $71.13_{b}$ & 2.00 & $0.90_{b}$ & 0.04 & $46.38_{b}$ & 1.60 & $5.27 \mathrm{~b}$ \\
\hline$P L$ & $29.12 b$ & 0.88 & $9.22_{c}$ & 0.20 & $61.55_{c}$ & 1.50 & $1.29 b$ & 0.03 & $2.82_{c}$ & 0.12 & $2.11_{c}$ \\
\hline SE & $51.20 \mathrm{a}$ & 1.65 & $10.68_{b}$ & 0.25 & $38.12_{d}$ & 1.20 & $23.73_{a}$ & 0.65 & $4.60_{c}$ & 0.14 & $0.74_{d}$ \\
\hline \multicolumn{12}{|l|}{$\mathrm{CO} 6$} \\
\hline $\mathrm{TL}$ & $7.01_{d}$ & 0.20 & $6.03_{d}$ & 0.18 & $85.98 a$ & 2.35 & $0.41_{b}$ & 0.02 & $56.47 a$ & 1.35 & $12.26_{a}$ \\
\hline TAG & $15.04_{c}$ & 0.32 & $14.12_{a}$ & 0.35 & $70.78_{b}$ & 2.10 & $0.83_{b}$ & 0.03 & $48.18_{b}$ & 1.62 & $4.71_{b}$ \\
\hline$P L$ & $28.52_{b}$ & 0.88 & $9.03_{c}$ & 0.25 & $62.39_{c}$ & 1.60 & $1.06_{b}$ & 0.02 & $2.74_{c}$ & 0.08 & $2.19_{c}$ \\
\hline SE & $51.46_{a}$ & 1.70 & $12.46_{b}$ & 0.34 & $36.08_{d}$ & 1.15 & $22.63_{a}$ & 0.60 & $3.75_{c}$ & 0.09 & $0.70_{d}$ \\
\hline \multicolumn{12}{|l|}{$\mathrm{CO}$} \\
\hline $\mathrm{TL}$ & $7.27 \mathrm{~d}$ & 0.22 & $6.72_{d}$ & 0.20 & $85.55_{a}$ & 2.40 & $0.48_{b}$ & 0.02 & $53.63_{a}$ & 1.30 & $11.77_{a}$ \\
\hline TAG & $13.73_{c}$ & 0.30 & $14.67_{a}$ & 0.33 & $71.52_{b}$ & 2.15 & $0.82_{b}$ & 0.03 & $46.90_{b}$ & 1.25 & $5.21_{b}$ \\
\hline$P L$ & $27.79_{b}$ & 0.80 & $8.74_{c}$ & 0.24 & $63.36_{c}$ & 1.70 & $1.18_{b}$ & 0.03 & $2.90_{c}$ & 0.10 & $2.28_{c}$ \\
\hline SE & $50.58 \mathrm{a}$ & 1.48 & $11.76_{b}$ & 0.20 & $37.66_{d}$ & 1.10 & $23.98 a$ & 0.70 & $3.77_{c}$ & 0.15 & $0.74_{d}$ \\
\hline \multicolumn{12}{|l|}{$\mathrm{CO8}$} \\
\hline $\mathrm{TL}$ & $7.15_{d}$ & 0.17 & $6.90_{d}$ & 0.18 & $85.61_{a}$ & 2.29 & $0.57_{b}$ & 0.03 & $51.95 a$ & 1.38 & $11.98_{a}$ \\
\hline TAG & $14.11_{c}$ & 0.40 & $16.30_{a}$ & 0.40 & $69.53_{b}$ & 1.98 & $0.85_{b}$ & 0.04 & $46.16_{b}$ & 1.30 & $4.93_{b}$ \\
\hline$P L$ & $27.13_{b}$ & 0.82 & $10.43_{c}$ & 0.28 & $62.31_{c}$ & 1.50 & $1.13_{b}$ & 0.03 & $3.10_{c}$ & 0.11 & $2.30_{c}$ \\
\hline SE & $55.74 a$ & 1.85 & $12.06_{b}$ & 0.32 & $32.20_{d}$ & 0.88 & $24.05_{a}$ & 0.75 & $4.74_{c}$ & 0.14 & $0.58_{d}$ \\
\hline
\end{tabular}


Table 2 The composition (\%) of fatty acid classes in total lipids and major lipid fractions from different genotypes of pot marigold seed oils (Continued)

\begin{tabular}{|c|c|c|c|c|c|c|c|c|c|c|c|}
\hline \multicolumn{12}{|l|}{ CO9 } \\
\hline $\mathrm{TL}$ & $7.04_{d}$ & 0.14 & $5.63_{c}$ & 0.16 & $86.94 a$ & 2.34 & $0.90_{b}$ & 0.03 & $54.80_{a}$ & 1.38 & $12.35 \mathrm{a}$ \\
\hline TAG & $10.92_{c}$ & 0.30 & $10.71_{a}$ & 0.31 & $78.27_{b}$ & 2.15 & $0.63_{b}$ & 0.04 & $50.59_{b}$ & 1.28 & $7.17_{b}$ \\
\hline$P L$ & $27.52_{b}$ & 0.72 & $9.04_{b}$ & 0.28 & $63.34_{c}$ & 1.52 & $1.39 \mathrm{~b}$ & 0.02 & $3.12_{c}$ & 0.06 & $2.30_{c}$ \\
\hline SE & $52.96_{a}$ & 1.60 & $10.97 a$ & 0.30 & $36.07_{d}$ & 1.05 & $24.58 a$ & 0.65 & $3.69_{c}$ & 0.07 & $0.68_{d}$ \\
\hline \multicolumn{12}{|c|}{$\mathrm{CO} 10$} \\
\hline $\mathrm{TL}$ & $6.74_{d}$ & 0.16 & $5.64_{c}$ & 0.14 & $87.22_{a}$ & 2.55 & $0.77_{\mathrm{b}}$ & 0.03 & $54.52_{a}$ & 1.35 & $12.95 \mathrm{a}$ \\
\hline TAG & $11.47_{c}$ & 0.31 & $10.94_{a}$ & 0.28 & $77.52_{b}$ & 2.20 & $0.58_{b}$ & 0.03 & $49.59_{b}$ & 1.18 & $6.76_{b}$ \\
\hline$P L$ & $26.32_{b}$ & 0.72 & $8.69_{b}$ & 0.25 & $64.90_{c}$ & 1.55 & $1.04_{b}$ & 0.02 & $3.04_{c}$ & 0.08 & $2.47_{c}$ \\
\hline SE & $54.07 \mathrm{a}$ & 1.65 & $10.34 a$ & 0.26 & $35.59_{d}$ & 0.95 & $24.60 \mathrm{a}$ & 0.68 & $3.43_{c}$ & 0.08 & $0.66_{d}$ \\
\hline \multicolumn{12}{|c|}{ CO11 } \\
\hline $\mathrm{TL}$ & $7.34_{d}$ & 0.18 & $5.48_{d}$ & 0.12 & $86.87 \mathrm{a}$ & 2.60 & $0.70_{b}$ & 0.03 & $55.93 a$ & 1.40 & $11.83 \mathrm{a}$ \\
\hline TAG & $11.96_{c}$ & 0.30 & $10.18 \mathrm{~b}$ & 0.25 & $77.77_{\mathrm{b}}$ & 2.25 & $0.55_{b}$ & 0.04 & $50.33_{b}$ & 1.20 & $6.50_{b}$ \\
\hline$P L$ & $28.45_{b}$ & 0.70 & $9.49_{c}$ & 0.22 & $62.02_{c}$ & 1.52 & $1.07_{b}$ & 0.03 & $2.47_{c}$ & 0.08 & $2.18_{c}$ \\
\hline SE & $53.90 \mathrm{a}$ & 1.75 & $11.07 \mathrm{a}$ & 0.27 & $35.03_{d}$ & 0.90 & $24.78_{a}$ & 0.80 & $3.19_{c}$ & 0.09 & $0.65 d$ \\
\hline
\end{tabular}

Values are given as mean \pm SD of three samples, analyzed individually in triplicate $(n=3 \times 3)$.

Means in the same column followed by different subscript letters indicate significant differences $(p<0.05)$ among lipid classes of each genotype of pot marigold (ANOVA "Tukey's Multiple Comparison Test"). TL - total lipids, TAG- triacylglycerols, PL- polar lipids, SE- sterol esters. SFAs- saturated fatty acids, MUFAsmonounsaturated fatty acids, PUFAs- polyunsaturated fatty acids, VLCSFAs- very long chain saturated fatty acids, $\sum$ CLNAs [18:3 (8trans, 10trans, 12cis) + 18:3 (8trans, 10trans,12trans)] - conjugated linolenic acids.

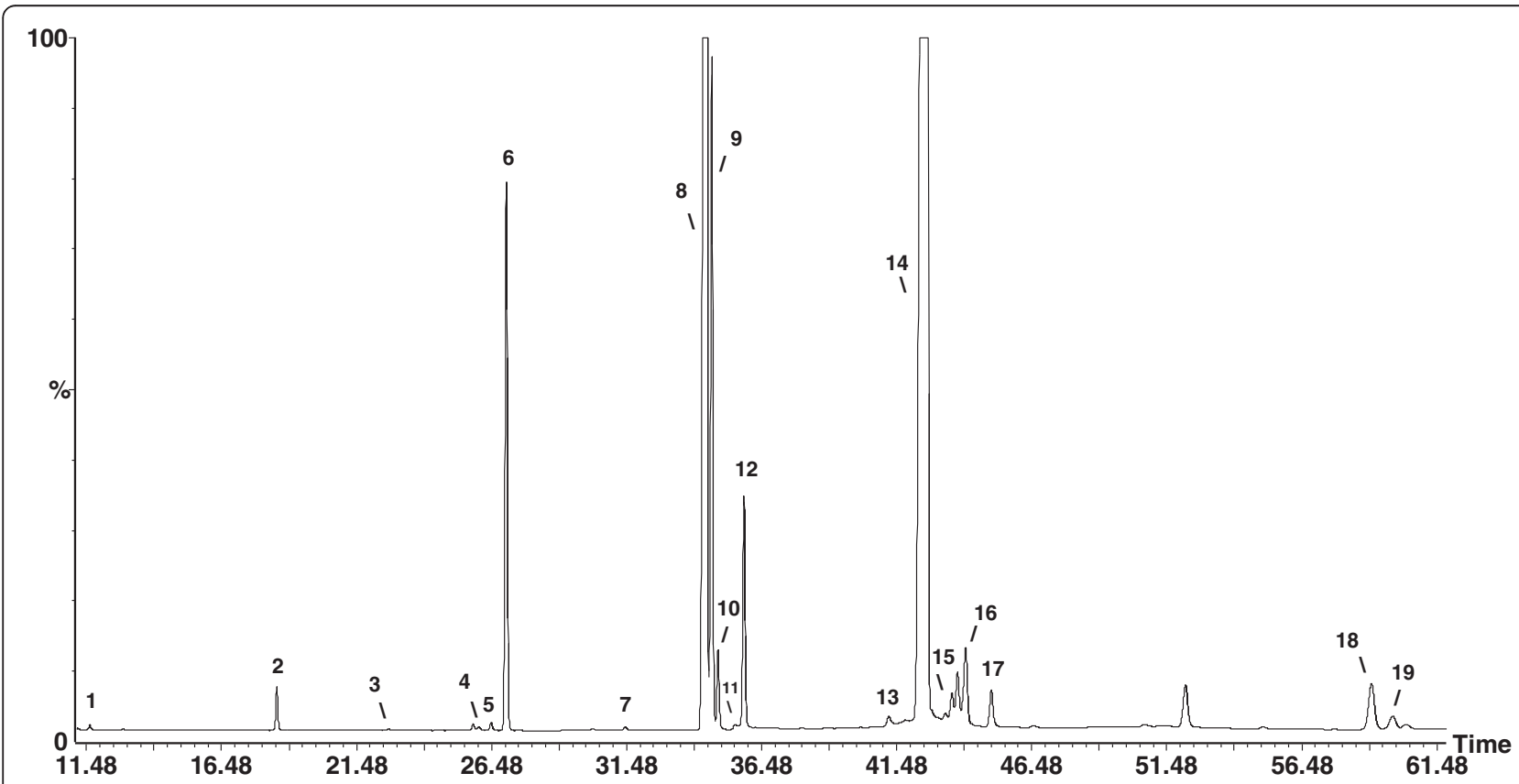

Figure 2 GC-MS chromatogram of FAMEs in the TLs of Calendula officinalis L. (CO2: cv. Prolifera nr. 214) seeds analysed with a BPx- 70 capillary column. Peaks: (1) lauric (12:0), (2) myristic (14:0), (3) pentadecanoic (15:0), (4) cis-7 hexadecenoic [16:1 (n-9)], (5) palmitoleic [16:1 (n-7)], (6) palmitic (16:0), (7) margaric (17:0), (8) linoleic [18:2 (n-6)], (9) oleic [18:1 (n-9)], (10) elaidic [18:1 (9t) (n-9)], (11) linoelaidicic [18:2 (9t,12t) (n-6)], (12) stearic (18:0), (13) a- linolenic [18:3 (n-3)], (14) calendic [18:3 (8t, $10 t, 12 c)(n-6)],(15)$ gondoic [20:1 (n-9)], (16) $\beta-$ calendic [18:3 (8t, 10t, 12t) (n-6)], (17) arachidic (20:0), (18) 9- hydroxy- trans-10, cis-12 octadecadienic (9- HODE), (19) behenic (22:0) acids. 


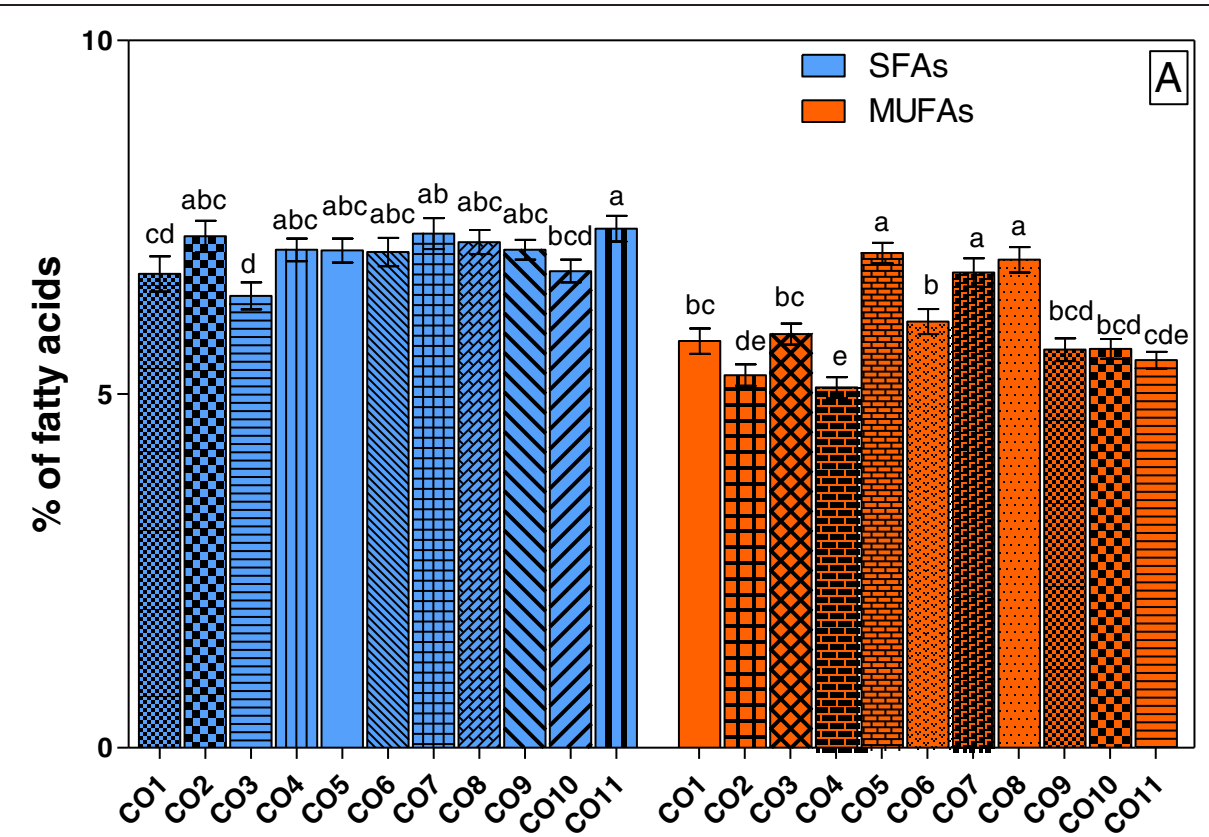

Fatty acid classes

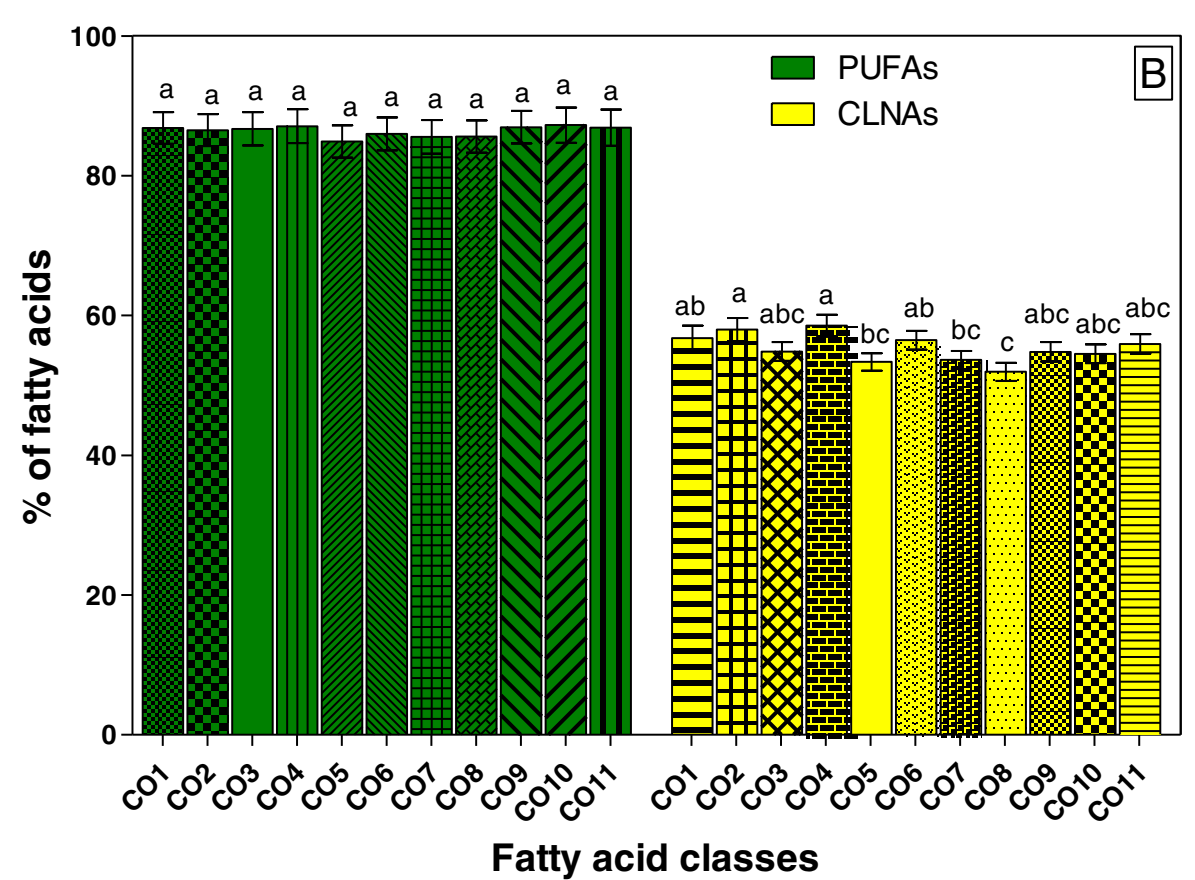

Figure 3 Comparative representation of fatty acid classes from total lipids of different genotypes of pot marigold (Calendula officinalis L.) seed oils. CO1- CO11, pot marigold (Calendula officinalis L.) genotypes. Values are mean \pm SD of three samples, analyzed individually in triplicate $(n=3 \times 3)$. Values with different letters (a-e) are significantly different $(p<0.05)$, using ANOVA "Tukey's Multiple Comparison Test". SFAs- saturated fatty acids, MUFAs- monounsaturated fatty acids, PUFAs- polyunsaturated fatty acids, CLNAs- conjugated linolenic acids.

and glycolipids. Transgenic soybean and Arabidopsis seeds engineered to synthesize calendic acid (by cloning of the fatty acid conjugase from Calendula) accumulated moderate level of conjugated fatty acids. Calendic acid was found at comparable levels in PC and TAG fractions ( $85 \%$ in the $s n-2$ position of $\mathrm{PC}$ ) proving that complex mechanisms involving both desaturation and transacylation processes are involved in the biosynthesis of rich CLNAs enriched TAG [26]. Same authors showed that accumulation of conjugated fatty acids in PC of transgenic plants (soybean and Arabidopsis) negatively affected the appearance and the germination rate of seeds due 
to the special chemical and physical properties of CLNAs. In consequence, the selection of valuable genotypes of Calendula which are able to produce large amounts of oil enriched in CLNAs still has an economical importance.

The levels of SFAs in SEs were significantly higher $(p<0.05)$ than in the corresponding lipid fractions of each genotype (Table 2). The amounts of saturated consisted mainly of palmitic (16:0) acid, very longchain saturated fatty acids (VLCSFAs) (more than 20 carbon atoms) and stearic (18:0) acid, respectively, and varied between 49.31\% (in CO1) and 55.74\% (in CO8) of total fatty acids from SEs (Tables 1 and 2). These observations are in agreement with the data reported by Zlatanov [38], Kallio et al. [39] and Yang et al. [40] about the fatty acid composition of the phospholipids and the SE fractions of other non-conventional seed oils.

In plant tissues, the very long-chain fatty acids $(\geq 20$ carbon atoms) are precursors for the synthesis of lipids, such as cuticular waxes (on the aerial plant surfaces), suberin (embedded in the cell walls of plant-environment interfaces), triacylglycerols (in seeds), and ceramides (in the cell membranes) [41,42].

The TL, TAG and PL fractions of all analyzed pot marigold genotypes exhibited very low proportions of VLCSFAs $(<1.50 \%$ of total fatty acids), whereas the SEs showed significantly higher $(\mathrm{p}<0.05)$ amounts of this type of fatty acids (from 20.59\% (CO4) to $24.78 \%$ (CO11)) (Table 2).

As shown in Table 2, in all extracts of pot marigold seeds, the PUFAs/SFAs ratios were significantly lower $(\mathrm{p}<0.05)$ in SE and PL fractions than in the corresponding TLs or TAGs. A comprehensive study of the Diabetes and Nutrition Study Group of the Spanish Diabetes Association showed that a dietary PUFAs/SFAs ratio $>0.4$ can greatly reduce the risk of onset of diabetic complications [43]. Moreover, in some earlier reports, the authors indicate that the values of this ratio comprised between 1.0 and 1.5, are optimal to reduce the risk of cardiovascular diseases $[44,45]$. Thus, the results of the present study show that the Calendula officinalis oil, whatever the genotype analyzed in this paper, may reduce the risk of cardiovascular diseases because both TLs and TAG presented PUFAs/ SFAs ratios values are closed to the recommended PUFA/ SFA intake by nutrition scientists.

\section{Conclusions}

In the present paper, seeds of eleven genotypes of Calendula officinalis L. originating from six different locations in Europe, cultivated in Romania (Transylvanian) were analyzed with respect to oil yields and fatty acid contents. To the best of our knowledge, data about detailed fatty acid composition of main lipid fractions in pot marigold seeds investigated in this study are not available in literature.

The oil content observed in most of the calendula seed samples studied was noted to range between 18 and $22 \mathrm{~g}$ oil/100 g seeds. The oil TAGs were similar in fatty acid composition to the TLs, containing substantial amounts of calendic and linoleic acids, making them excellent dietary sources of PUFAs, especially of CLNAs. The PL fractions were highly unsaturated, due to the dominance of the linoleic acid in their structures. A clear characteristic of the SEs from the pot marigold seed oils analyzed were the significantly high levels of SFAs, with considerable amounts of VLCSFAs.

The compositional differences between the genotypes should be considered when breeding and exploiting the calendula seeds for industrial, nutraceutical or pharmacological purposes.

\section{Materials and methods}

\section{Seeds and chemicals}

Eleven genotypes of Calendula officinalis L. originating from six different locations in Europe (botanical gardens and institutes) (Table 3) were cultivated on

Table 3 Genotypes of Calendula officinalis L. (CO) evaluated

\begin{tabular}{lcc}
\hline Samples & Genotypes & Sources \\
CO1 02 & C. officinalis L. D.a & Humboldt-Universität zu Berlin, Institut für Biologie, Germany \\
CO3 & cv. Prolifera nr. 214 & Botanische Garten der Universität Göttingen, Germany \\
CO4 & Bon-Bon Orange & National Botanic Garden of Latvia, Salaspils, Latvia \\
CO5 & Bon-Bon Mix' & Hortus Botanicus Fominianus, Kiev, Ukraine \\
CO6 & cv. Radio & Ökologisch-Botanischer Garten der Universität Bayreuth, Germany \\
CO7 & C. officinalis L. PL & Hortus Farmacognosticus Academiae Medicinalis, Lublin, Poland \\
CO8 & C. officinalis L. I & Instituto di Botanica e Orto Botanico Pierino Scaramella, Italy \\
CO9 & cv. Prycosnovjenie & National Botanical Gardens Timirjazevska, Kiev, Ukraine \\
CO10 & cv. Pacific Beauty & National Botanical Gardens Timirjazevska, Kiev, Ukraine \\
CO11 & cv. Zelenoye Serdtse & National Botanical Gardens Timirjazevska, Kiev, Ukraine \\
\hline
\end{tabular}


experimental fields of the University of Agricultural Sciences and Veterinary Medicine of Cluj- Napoca (Romania). The crops were established in the first half of May 2011, to a target population of 40 plants $\mathrm{m}^{-2}$. Plot area was prepared before (autumn of 2010) by fertilization with animal manure. Nitrogen- based fertilizers were applied during the vegetation period. The seeds were harvested manually at full maturity (end of September-beginning of October).

All reagents (used for the oil extraction, fractionation and fatty acid methyl esters (FAMEs) preparation) and lipid standards (used for identification of the lipid class) were of chromatographic grade (Sigma-Aldrich (St. Louis, MO, USA)). The thin layer chromatography (TLC) plates (silica gel $60 \mathrm{~F} 254,20 \times 20 \mathrm{~cm}$ ) were purchased from Merck (Darmstadt, Germany).The FAMEs standard (37 component FAME Mix, SUPELCO, catalog No: 47885-U) were purchased from Supelco (Bellefonte, PA, USA).

\section{Oil extraction and fractionation}

The oils were extracted from $5 \mathrm{~g}$ of seeds, using a methanol/chloroform extraction procedure, according to Yang et al. [36] and Dulf et al. [46]. The sample was homogenized in $50 \mathrm{~mL}$ methanol for $1 \mathrm{~min}$ using a homogeniser (MICCRA D-9, Germany), $100 \mathrm{~mL}$ chloroform was added, and homogenization was continued for further $2 \mathrm{~min}$. The mixture was filtered under vacuum through a Buchner funnel and the solid residue was resuspended in $150 \mathrm{~mL}$ of chloroform: methanol $(2: 1, \mathrm{v} / \mathrm{v})$ and homogenized for another $3 \mathrm{~min}$. The mixture was filtered again and washed with $150 \mathrm{~mL}$ chloroform: methanol $(2: 1, \mathrm{v} / \mathrm{v})$. The filtrates were combined and cleaned with $0.88 \%$ potassium chloride water solution and methanol: water $(1: 1, \mathrm{v} / \mathrm{v})$ solution. The bottom layer (with the purified lipids) was filtered before the solvent was rotary evaporated. The total lipids recovered were transferred to vials with $4 \mathrm{~mL}$ chloroform (stock solution), and stored at $-18^{\circ} \mathrm{C}$ for further analysis.

Neutral and polar lipid fractions were separated by TLC [47]. Lipid aliquots ( $0.2 \mathrm{ml}$ of stock solution) were applied on the TLC plates and then developed in a mixture of petroleum ether: diethyl ether: acetic acid (85:15:1, v/v/v), sprayed with 2', 7'-dichlorofluoroscein/ methanol $(0.1 \% \mathrm{w} / \mathrm{v})$ and viewed under UV light $(254 \mathrm{~nm})$ [48]. The lipid classes were identified using commercial standards and then scraped from the TLC plates. The first band (at the origin of the plates), corresponding to the PLs was eluted from silica layer with methanol: chloroform $(1: 1, \mathrm{v} / \mathrm{v})$, and the upper two major bands of TAGs and SEs respectively were eluted with chloroform. The samples were filtered, the solvent was removed and the dry residue was subjected to transesterification and gas chromatographic (GC) analysis.

\section{Fatty acid analysis}

The total lipid, PL, TAG and SE fractions were derivatized by sodium methoxide catalysis [49]. The FAMEs were determined by gas chromatography-mass spectrometry (GC-MS), using a PerkinElmer Clarus $600 \mathrm{~T}$ GC-MS (PerkinElmer, Inc., Shelton, U.S.A.) equipped with a, BPx- 70 capillary column $(60 \mathrm{~m} \times 0.25 \mathrm{~mm}$ i.d., $0.25 \mu \mathrm{m}$ film; SGE, Ringwood, Australia). The initial oven temperature was $140^{\circ} \mathrm{C}$, increased to $220^{\circ} \mathrm{C}$ with a rate of $2^{\circ} \mathrm{C} / \mathrm{min}$ and then held at this temperature for $25 \mathrm{~min}$. Flow rate of the carrier gas $\mathrm{He}$ and the split ratio were $0.8 \mathrm{ml} / \mathrm{min}$ and $1: 24$, respectively. The injector temperature was $210^{\circ} \mathrm{C}$. The positive ion electron impact (EI) mass spectra was recorded at an ionization energy of $70 \mathrm{eV}$ and a trap current of $100 \mu \mathrm{A}$ with a source temperature of $150^{\circ} \mathrm{C}$. The mass scans were performed within the range of m/z: 22-395 at a rate of 0.14 $\mathrm{scan} / \mathrm{s}$ with an intermediate time of $0.02 \mathrm{~s}$ between the scans. The injected volume was $0.5 \mu \mathrm{l}$. Identification of FAMEs was achieved by comparing their retention times with those of known standards (37component FAME Mix, SUPELCO \# 47885-U) and the resulting mass spectra to those in our database (NIST MS Search 2.0).

\section{Statistics}

Three different samples of Calendula seeds for each genotype were assayed. The analytical results reported for the fatty acid compositions, are the average of triplicate measurements of three independent oils $(n=3 \times 3)$. The assumptions of equality of variances and normal distribution of errors were checked for the tested response variables. Since the assumptions were satisfied, data were subjected to one-way ANOVA (repeated measures ANOVA) and Tukey's post hoc test. Statistical differences among oil samples were estimated using: "Kruskal-Wallis non-parametric test" followed by "Dunn's Multiple Comparison Test" (Graph Pad Prism Version 4.0, Graph Pad Software Inc., San Diego CA). A probability value of $p<0.05$ was considered to be statistical significant.

\section{Abbreviations \\ CLNAs: Conjugated linolenic acids; TLs: Total lipids; TAGs: Triacylglycerols; PLs: Polar lipids; SEs: Sterol esters; PUFAs: Polyunsaturated fatty acids; SFAs: Saturated fatty acids; MUFAs: Monounsaturated fatty acids; VLCSFAs: Very long-chain saturated fatty acids; PC: Phosphatidylcholine; CO: Calendula officinalis; FAMEs: Fatty acid methyl esters; TLC: Thin layer chromatography; GC-MS: Gas chromatography-mass spectrometry.}

Competing interests

The authors declare that they have no competing interests.

Authors' contributions

FVD and DP carried out the experimental design, interpretation of results and preparation of the paper. ADB contributed to the extraction of lipids. AP contributed to the separation, identification and quantification of the lipid fractions and fatty acids from the samples. All authors read and approved the final manuscript. 


\section{Acknowledgements}

This work was supported by the POSDRU/89/1.5/S/52432 project („Organising the National Interest Postdoctoral School of Applied Biotechnologies with Impact on Romanian Bioeconomy") and by a grant of the Romanian National Authority for Scientific Research, CNCS - UEFISCDI project number PN-II-ID-PCE-2011-3-0721.

Received: 30 September 2012 Accepted: 14 January 2013

Published: 17 January 2013

\section{References}

1. Ercetin T, Senol FS, Orhan IE, Toker G: Comparative assessment of antioxidant and cholinesterase inhibitory properties of the marigold extracts from Calendula arvensis L. and Calendula officinalis L. Ind Crop Prod 2012, 36:203-208

2. Wojciak-Kosior M, Matysik G, Soczewinski E: Investigations of phenolic acids occurring in plant components of Naran N by HPLC and HPTLC densitometric methods. Herba Pol 2003, 49:194-201.

3. Kishimoto S, Maoka T, Sumitomo K, Ohmiya A: Analysis of carotenoid composition in petals of Calendula (Calendula officinalis L.). BiosCi Biotechnol Biochem 2005, 69:2122-2128.

4. Re TA, Mooney D, Antignac E, Dufour E, Bark I, Srinivasan V, Nohynek G: Application of the threshold of toxicological concern approach for the safety evaluation of calendula flower (Calendula officinalis) petals and extracts used in cosmetic and personal care products. Food Chem Toxicol 2009, 47:1246-1254.

5. Saleem M: Lupeol, a novel anti-inflammatory and anti-cancer dietary triterpene. Cancer Lett 2009, 285:109-115.

6. Kaurinovic B, Popovic M, Cebovic T, Mimika-Dukic N: Effects of Calendula officinalis L. and Taraxacum officinale Weber (Asteraceae) extracts on production of $\mathrm{OH}$ radicals. Fresenius Environ Bull 2003, 12:250-253.

7. Cetkovic GS, Djilas SM, Canadanovic-Brunet JM, Tumbas VT: Antioxidant properties of marigold extracts. Food Res Int 2004, 37:643-650.

8. Miliauskas $G$, Venskutonis PR, van Beek TA: Screening of radical scavenging activity of some medicinal and aromatic plant extracts. Food Chem 2004 85:231-237

9. Muley BP, Khadabadi SS, Banarase NB: Phytochemical constituents and pharmacological activities of Calendula officinalis Linn (Asteraceae). Tropical J Pharm Res 2009, 8:455-465.

10. Vodnar DC: Inhibition of Listeria monocytogenes ATCC 19115 on ham steak by tea bioactive compounds incorporated into chitosan-coated plastic films. Chem Central J 2012, 6:74.

11. Badami RC, Patil KB: Structure and occurrence of unusual fatty acids in minor seed oil. Prog Lipid Res 1981, 19:119-153.

12. Aitzetmüller K: Capillary GLC fatty acid fingerprints of seed lipids - A tool in plant chemotaxonomy? J High Resol Chromatogr 1993, 16:488-490.

13. McLean J, Clark AH: The isolation of octadec-8:10:12-trienoic acid from marigold seed oil. J Chem Soc 1956, I:777-778.

14. Chisholm MJ, Hopkins CY: Conjugated fatty acids of Tragopogon an Calendula seed oils. Can J Chem 1960, 38:2500-2507.

15. Tulloch AP: 13 C Nuclear Magnetic Resonance spectroscopic analysis of seed oils containing conjugated unsaturated acids. Lipids 1982, 17(80):546-551.

16. Saleem M, Zaka G, Shakir N, Khan SA: Studies on marigold seed oil and seed meal. Fette, Seifen, Anstrichm 1986, 88:178-180

17. Crombie L, Holloway SJ: The biosynthesis of calendic acid, octadeca-(8E, $10 E, 12 Z)$-trienoic acid, by developing marigold seeds: origins of $(E, E, Z)$ and $(Z, E, Z)$ conjugated triene acids in higher plants. J Chem Soc, Perkin Trans 1985, 1:2425-2434.

18. Fritsche K, Hornung E, Petzsch N, Renz A, Feussner I: Isolation and characterization of a calendic acid producing $(8,11)$-linoleoyl desaturase. FEBS Lett 1999, 462(3):249-253.

19. Cahoon EB, Ripp KG, Hall SE, Kinney AJ: Formation of conjugated delta8, delta10-double bonds by delta12-oleic-acid desaturase-related enzymes: biosynthetic origin of calendic acid. J Biol Chem 2001, 276(4):2637-2643.

20. Qiu X, Reed DW, Hong H, MacKenzie SL, Covello PS: Identification and analysis of a gene from Calendula officinalis encoding a fatty acid conjugase. Plant Physiol 2001, 125(2):847-855.
21. Reed DW, Savile C, Qiu X, Buist PH, Covello PS: Mechanism of 1,4 dehydrogenation catalyzed by a fatty acid $(1,4)$-desaturase of Calendula officinalis. Eur J Biochem 2002, 269(20):5024-5029.

22. Derksen JTP, Cuperus PF, Kolster P: Renewable resources in coatings technology: a review. Prog Org Coat 1996, 27(1):45-53.

23. Metzger JO, Bornscheurer $\mathrm{U}$ : Lipids as renewable resources: current state of chemical and biotechnological conversion and diversification. Appl Microbiol Biotechnol 2006, 71(1):13-22.

24. Hennessy AA, Ross RP, Devery R, Stanton C: The health promoting properties of the conjugated isomers of a-linolenic acid. Lipids 2011, 46:105-119.

25. Cromack HTH, Smith JM: Calendula officinalis production potential and crop agronomy in Southern England. Ind Crop Prod 1998, 7:223-229.

26. Cahoon EB, Dietrich CR, Meyer K, Damude HG, Dyer JM, Kinney AJ: Conjugated fatty acids accumulate to high levels in phospholipids of metabolically engineered soybean and Arabidopsis seeds. Phytochem 2006, 67(12):1166-1176.

27. Cahoon EB, Shockey JM, Dietrich CR, Gidda SK, Mullen RT, Dyer JM: Engineering oilseeds for sustainable production of industrial and nutritional feedstocks: solving bottlenecks in fatty acid flux. Curr Opin Plant Biol 2007, 10:236-244.

28. Chardigny JM, Hasselwander O, Genty M, Kraemer K, Ptock A, Sebedio JL: Effect of conjugated FA on feed intake, body composition, and liver FA in mice. Lipids 2003, 38(9):895-902.

29. Suzuki R, Noguchi R, Ota T, Abe M, Miyashita K, Kawada T: Cytotoxic effect of conjugated trienoic fatty acids on mouse tumor and human monocytic leukemia cells. Lipids 2001, 36(5):477-482.

30. Yasui Y, Hosokawa M, Kohno H, Tanaka T, Miyashita K: Growth inhibition and apoptosis induction by all-trans-conjugated linolenic acids on human colon cancer cells. Anticancer Res 2006, 26(3A):1855-1860.

31. Bhaskar N, Masashi H, Yumiko Y, Rikako S, Hiroyuki K, Takuji T, Kazuo M: Chemopreventive effects of conjugated linolenic acids (CLN) occurring in plant seed oils. Curr Nutr Food Sci 2007, 3(4):309-318.

32. Ul'chenko NT, Glushenkova Al, Mukhamedova KS: Lipids of Calendula officinalis. Chem Nat Compd 1998, 34(3):272-274.

33. Pintea A, Dulf F, Bele C, Andrei S: Fatty acids distribution in the lipid fractions of Calendula officinalis L. seeds oil. Chem Listy 2008, 102(15):749-750.

34. Özgül-Yücel S: Determination of conjugated linolenic acid content of selected oil seeds grown in Turkey. J Am Oil Chem Soc 2005, 82(12):893-897.

35. Angelini LG, Moscheni $E$, Colonna G, Belloni P, Bonari E: Variation in agronomic characteristics and seed oil composition of new oilseed crops in central Italy. Ind Crops Prod 1997, 6:313-323.

36. Yang BR, Kallio HP: Fatty acid composition of lipids in sea buckthorn (Hippophaë rhamnoides L.) berries of different origins. J Agric Food Chem 2001, 49:1939-1947.

37. Muuse BG, Cuperus FP, Derksen JTP: Composition and physical properties of oils from new oil seed crops. Ind Crop Prod 1992, 1(1):57-65.

38. Zlatanov MD: Lipid composition of Bulgarian chokeberry, black currant and rose hip seed oils. J Sci Food Agric 1999, 79:1620-1624.

39. Kallio H, Yang B, Peippo P, Tahvonen R, Pan R: Triacylglycerols, glycerophospholipids, tocopherols, and tocotrienols in berries and seeds of two subspecies (ssp. sinensis and mongolica) of sea buckthorn (Hippophaë rhamnoides). J Agric Food Chem 2002, 50:3004-3009.

40. Yang B, Koponen J, Tahvonen R, Kallio H: Plant sterols in seeds of two species of Vaccinium (V. myrtillus and V. vitis-idaea) naturally distributed in Finland. Eur Food Res Technol 2003, 216:34-38.

41. Lee SB, Jung SJ, Go YS, Kim HU, Kim JK, Cho HJ, Park OK, Suh MC: Two Arabidopsis 3-ketoacyl CoA synthase genes, KCS20 and KCS2/DAISY, are functionally redundant in cuticular wax and root suberin biosynthesis, but differentially controlled by osmotic stress. Plant J 2009, 60:462-475.

42. Baciu AD, Mihalte $L$, Sestras $A$, Sestras $R$ : Variability of decorative traits, response to the Aphis fabae attack and RAPD diversity in different genotypes of Calendula. Not. Bot. Hort. Agrobot. Cluj 2010, 38(3):265-270.

43. Diabetes and Nutrition Study Group of the Spanish Diabetes Association (GSEDNu): Diabetes nutrition and complications trial: adherence to the ADA nutritional recommendations, targets of metabolic control, and onset of diabetes complications. A 7-year, prospective, population- 
based, observational multicenter study. J Diabetes Complicat 2006, 20:361-366.

44. Kang MJ, Shin MS, Park JN, Lee SS: The effects of polyunsaturated: saturated fatty acids ratios and peroxidisability index values of dietary fats on serum lipid profiles and hepatic enzyme activities in rats. Brit $J$ Nutr 2005, 94:526-532.

45. Guo Z, Miura K, Turin TC, Hozawa A, Okuda N, Okamura T, Saitoh S, Sakata K, Nakagawa H, Okayama A, Yoshita K, Kadowaki T, Choudhury SR, Nakamura Y, Rodriguez BL, Curb DJ, Elliott P, Stamler J, Ueshima H: Relationship of the polyunsaturated to saturated fatty acid ratio to cardiovascular risk factors and metabolic syndrome in Japanese: the INTERLIPID study. J Atheroscler Thromb 2010, 17:777-784.

46. Dulf FV, Andrei S, Bunea A, Socaciu C: Fatty acid and phytosterol contents of some Romanian wild and cultivated berry pomaces. Chem Pap 2012, 66(10):925-934.

47. Dulf FV: Fatty acids in berry lipids of six sea buckthorn (Hippophae rhamnoides L., subspecies carpatica) cultivars grown in Romania. Chem Cent J 2012, 6:106.

48. Kramer JKG, Cruz-Hernandez C, Deng Z, Zhou J, Jahreis G, Dugan MER: Analysis of conjugated linoleic acid and trans 18:1 isomers in synthetic and animal products. Am J Clin Nutr 2004, 79:1137S-1145S.

49. Christie WW: Preparation of methyl ester and other derivatives. In Gas Chromatography and Lipids. A Practical Guide. Edited by Christie W, Glasgow. Great Britain: The Oily Press; 1989:36-47.

doi:10.1186/1752-153X-7-8

Cite this article as: Dulf et al:: Fatty acid composition of lipids in pot marigold (Calendula officinalis L.) seed genotypes. Chemistry Central Journal 2013 7:8.

\section{Publish with ChemistryCentral and every scientist can read your work free of charge \\ "Open access provides opportunities to our colleagues in other parts of the globe, by allowing anyone to view the content free of charge." \\ W. Jeffery Hurst, The Hershey Company. \\ - available free of charge to the entire scientific community \\ - peer reviewed and published immediately upon acceptance \\ - cited in PubMed and archived on PubMed Central \\ - yours - you keep the copyright \\ Submit your manuscript here: \\ http://www.chemistrycentral.com/manuscript/<smiles>c1ccccc1</smiles> 